\title{
Why Stay for Less Pay? An Exploratory Study into the Motivations of Accountants in a Faith-Based, Non-Profit Organization in Australia
}

\author{
Bernadene Erasmus, Keith Howson \\ School of Business, Avondale University, Cooranbong, Australia \\ Email: berasmus@bigpond.com
}

How to cite this paper: Erasmus, B., \& Howson, K. (2021). Why Stay for Less Pay? An Exploratory Study into the Motivations of Accountants in a Faith-Based, Non-Profit Organization in Australia. Psychology, 12, 1756-1780.

https://doi.org/10.4236/psych.2021.1211106

Received: August 31, 2021

Accepted: November 21, 2021

Published: November 24, 2021

Copyright $\odot 2021$ by author(s) and Scientific Research Publishing Inc. This work is licensed under the Creative Commons Attribution International License (CC BY 4.0).

http://creativecommons.org/licenses/by/4.0/ (c) (i) Open Access

\begin{abstract}
Retention of top talent represents a critical challenge for non-profit organizations restricted by limited resources. Factors impacting intention to leave have been widely studied. Far less attention has been given to individual work motivation in specific context. This study explored the motivation of accountants in an Australian faith-based non-profit organization to further understand the factors that impact satisfaction with employment and intention to remain. The sample represents both management and employee perspectives and reflects a diversity of cultural background. From an analysis of the data a substantive theory was developed. Core theoretical categories: Purpose, Progress, Proximity were identified as primary to the motivation of this sample. The potential of these categories to be operationalized through the dynamic elements of Connection, Growth and Balance presents practical recommendations for management practice. Findings from this inquiry add insight into Spirituality as a distinctive motivation factor.
\end{abstract}

\section{Keywords}

Retention, Accountants, Faith-Based, Non-Profit, Management

\section{Introduction}

In a volatile and innovative business environment, the competition amongst business to secure top talent becomes increasingly tough (Brundage \& Koziel, 2010; Colleran et al., 2010; Brandel, 2002; Kirsch, 2007; Holland, Sheehan, \& De Cieri, 2007; Adhikari, 2009). Despite advances in technology, the acquisition and retention of valued employees remain a key focus. Software has replaced some of 
the manual procedures in accounting but in instances where relationship connection with stakeholders and co-workers has traditionally played a vital role in business operations, valued employees are required with not only technical skills but also exceptional human relationship ability. This is particularly true of accounting departments which deal with older clients who may not have access to computers or computer skills.

Australian business organizations are not exempt from the ongoing challenge of recruiting and retaining staff within an unpredictable economic climate. Contemporary trends suggest that retention is overtaking recruitment as the primary challenge of management (Kirsch, 2007). In Australia, the business community is acknowledging the significance of retention and development as a source of competitive advantage in the "war for talent" (Holland, Sheehan, \& De Cieri, 2007).

Within the contemporary business sector, the significance of the non-profit sector, seen as distinct from the for-profit sector, is gaining momentum. Increasingly, its potential for providing social services is recognized by governments (Briggs, Peterson, \& Gregory, 2010; Cnaan \& Curtis, 2013; Helmig, Jagers, \& Lapsley, 2004; Wymer, Riecken, \& Yavas, 1996). As governments look to non-profit organizations to pick up the burden of social services, the question of non-profit sustainability comes under the spotlight.

Within a covid impacted environment, the sustainability of non-profit organizations assumes an even greater challenge. The volatile job and investment markets are having a significant impact on donations which will have a direct effect on the ability to retain staff (Deitrick, Tinker, Young, Strawser, Meschen, Menriques, \& Beatty, 2020). Projected statistics are expected to reflect a worsening scenario. It becomes evident that the retention of core staff is regarded as crucial for non-profit employee management (Brandel, 2002). Reducing turnover is assuming a top priority (Kang et al., 2015).

Pre-Covid attrition in non-profit organizations in areas of Australia is estimated at between $26 \%$ and $30 \%$ per annum (Keys, 2017). This represents a significant portion of the non-profit workforce whose loss in terms of financial and non-financial cost, has the capacity to negatively impact the competency and effectiveness of organizations. The impact of turnover at this rate has the potential too of undermining the ability of non-profit organizations to achieve their mission goal and consequently impact the core value of their existence (Colleran et al., 2010).

Non-profit organizations remain distinct from their for-profit counterparts in that they have no access to equity capital nor do they distribute resources to stakeholders (Helmig et al., 2004). Despite these challenges, non-profit organizations as a rule compete with corporates and the for-profit sector for the recruitment and retention of top talent with comparatively limited resources and job security (Colleran et al., 2010). The gap in earnings between employees in the for-profit sector and those employed in the non-profit sector has been estimated 
at 59\% (Frank, 1993). There is consensus in the literature that executives and top managers in non-profit organizations earn persistently less than their counterparts in other sectors (Handy \& Katz, 1998) even though their job descriptions are equally complex to those in other sectors (Roomkin \& Weisbrod, 1999).

Despite these discrepancies, non-profit organizations continue to attract highly qualified workers. In the field of accountancy, as an example, where the turnover rate among professional accountants is reported to be disproportionately high (Twiname, Samujh, \& Val Lamoen, 2012), non-profit organizations continue to recruit employees of whom 69\% have education levels at college or greater, compared to $45.6 \%$ of their for-profit counterparts (Leete, 2000). It has also been found that despite lower wages, non-profit workers indicate stronger motivation and higher levels of satisfaction than their counterparts in for-profit organizations (Benz, 2005).

These considerations present an intriguing anomaly: if highly qualified workers are attracted to work for less pay and advancement opportunities and express comparatively higher levels of work satisfaction, why are attrition rates in specific fields such as accounting so high? Indeed, why would these employees remain in these organizations? These considerations thrust increased understanding of employee retention in non-profit organizations into the critical arena of thought (Brandel, 2002; Kang, Huh, Cho, \& Auh, 2015). The questions gave rise to the rationale for inquiry into the experience of accountants in non-profit organizations in a way which would present a more holistic explanation of the phenomenon.

Although the question of employee turnover has attracted extensive inquiry, there is far less research on why they choose to stay (Christeen, 2015). One pathway of addressing anomalies is through the development of theory. Clayton Christensen (2016), named by The Economist as the most influential business management thinker of the 21 century, writes that in many ways good theory is more accurate than data in that data speaks to the past while good theory speaks to the future. Contrary to perceptions in business management that theory is impractical, good theory is "consummately practical" (Christensen, 2016). This stance endorses that of Lewin who concluded that there is nothing so practical as a good theory (Lewin, 1946). The current study is launched on the premise that the development of a substantive theory has the potential to offer insight into the motivation of current and professional workers which will potentially facilitate practical management in promoting the retention of talented employees in specific context.

In summary: the rationale for this inquiry transpired from a consideration of the vital necessity of retaining highly qualified staff in non-profit organizations operating in a volatile and unpredictable business climate. A reading of the extant literature on staff retention in this field proposed the potential limitation of mainly quantitative study. The general scope of factors impacting retention and the need to distinguish and define factors relating to employment experience in non-profit organizations in particular, suggested a qualitative inquiry into indi- 
vidual experience to increase holistic understanding of the phenomenon. Further the noted absence of inquiry into distinctive characteristics of specific organizations such as spirituality in faith-based non-profit organizations, necessitated further inquiry. A principal objective of this inquiry is to demonstrate the practicability of theory in order to address a general misconception, referred to by Professor Christensen (2016), that the business community often regards academic theory to be of little practical significance for business practice.

The inquiry will start with a consideration of the literature relating to employee motivation. The next section will outline the selection of a grounded study approach as a best fit for addressing the research phenomenon. The collection and analysis of data will be addressed in this section on Methodology. This will be followed by an analysis of the data from which a substantive theory is developed. The strengths and limitations of the study will be considered before the discussion section and concluding remarks ends the study.

\section{Context}

But first, consideration is given to the context chosen for the inquiry into accountant experience.

In their study, Twiname, Samujh, \& Van Lamoen (2012) found that the accounting profession was grappling with the problem of employee intention to leave. Inquiry into the recruitment and retention of the accounting profession has been undertaken in New Zealand and Australia predominantly applying survey measures and no qualitative research could be found that explored the motivation of accountants in the specific context of an Australian faith-based non-profit organization.

The treasury department of a non-profit organization in New South Wales, Australia, was chosen for this study specifically for its representation of employee diversity in terms of gender, age, culture and disability. It operates in two different localities in New South Wales: The South Pacific Division is situated in Wahroonga, Sydney. It is the administrative entity for the South Pacific region which includes Australia, New Zealand, Papua New Guinea and other Pacific nations. The division oversees a range of ancillary social services through almost 200 churches in the region. The second division, the Northern New South Wales Conference, is located in Wallsend, Newcastle, where it supplies support services to the area. The core values of the organization are listed in the financial report of July 2021: spirituality, ministry, nurture, teamwork and accountability.

Faith-based organizations have been identified in the literature as needing further inquiry. Bielefeld and Cleveland (2013) found that publications of non-profit, faith-based organizations have declined since 2008. The authors suggest the faith factor distinguishes FBOs from non-FBO providers. The organizations are similar, however, in that leadership of both wrestle with the attraction and retention of highly motivated employees (Bassous, 2015). The faith-based context is pertinent in that it offers an opportunity to include the impact of spirituality in an 
inquiry into the motivation of employees.

\section{Literature Review}

\subsection{Introduction}

The use of extant literature in a grounded theory study is the source of ongoing debate. While the discussion is acknowledged, this study will offer only a brief explanation of the current approach adopted as it relates to the inquiry. The question of theoretical pre-knowledge has resulted in a division of stance from Glaser's position that codes and categories emerge directly from the data as noted in Glaser \& Strauss (2008) to Strauss \& Corbin's (1990) view that theoretical pre-knowledge flows into the data's interpretation (Reichertz, 2007). The position taken by the current authors is that the development of theory cannot preclude theoretical pre-knowledge and that inquiry based on effective in-depth interview questions cannot claim tabula rasa (Strauss \& Corbin, 1990). Consequently, the inclusion of a literature review in this study is not meant as a framework but agrees with the view of Stern (2007) that it is important to situate research in a body of relevant literature to give credit to the work of others in the field and to show that the current work furthers understanding of prevailing ideas on the phenomena.

\subsection{Motivation: The Field}

Human motivation has remained an intriguing question since the era of Greek philosophy from where it evolved to the fields of psychology and behavioural sciences. Motivation essentially refers to the "why?" of human behavior (Vallerand, 2012). The introduction of employee motivation into the conversation has only comparatively recently entered the arena of business and management studies (Bassous, 2015).

According to Meneghetti (1995), theories on motivation may be divided into two broad categories: process-based theories and content-based theories. Content-based theories apply to specific motivation needs and include; Maslow's Hierarchy of Needs, Herzberg's 2-factor Theory and McClelland's Needs Theory. Process-based theories are more generally related to the interaction between behaviours, needs and rewards as seen in the Equity Theory and the Objective Theory. Other contemporary theories on motivation include Self-Determination Theory, Goal Setting Theory, Self Efficacy Theory and Reinforcement Theory.

The cursory referral to motivation theory is meant to highlight the context for the current study and is not introduced as a framework of inquiry. The reference to the more classic motivational theories does not exclude the acknowledgement of more contemporary conversations but further discussion lies outside the limits of the current study.

\subsection{Motivation: At Work}

Work motivation remains a central topic of organizational studies as it helps to 
explain what factors attract and retain individuals in particular jobs (Lee \& Wilkins, 2011). A reading of the literature indicates that within the current employment environment, attracting and retaining employees remains a dominant focus of organizational management (Adhikari, 2009; Colleran et al., 2010; Ghosh et al., 2013; Kang, Huh, Cho, \& Auh, 2015; Moynihan \& Pandey, 2008). Although non-profit organizations face some similar challenges in a bid to retain top talent, there are distinct differences in the working environment of the non-profit sector (Lee \& Wilkins, 2011). Current studies focus primarily on job choice motivation within the public and private sector (Park \& Ward, 2012). The unique nature of non-profit organizations requires an understanding of job choice motivations in this sector. The literature proposes that employees in the non-profit sector have a strong commitment to organizational philosophy which is subordinate to monetary gains (Handy \& Katz, 1998). This suggests that employees in non-profit organizations may choose to work there for other than financial gain and are motivated by the desire to help the community and serve others (Perry \& Wise, 1990). Does this imply that despite the fact that managerial wages in the non-profit sector are persistently lower than in other sectors, lower wages will not deter employees who are committed to the cause (Handy \& Katz, 1998)?

\subsection{Motivation: Extrinsic and Intrinsic}

Intrinsic and extrinsic motivation fits well with an inquiry into individual employee experience as factors both inside and outside of the individual are considered to affect personal motivation (Vallerand, 2012).

Extrinsic motivation includes both personal and social benefits and includes monetary incentives and task-related rewards. In many faith-based organizations extrinsic rewards may be restricted to non-monetary rewards which are essentially altruistic (Netting et al., 2006). These include performance rewards, recognition of service to others, compelling work and satisfaction (Gagne \& Deci, 2005).

A reading of the literature suggests that employees in non-profit organizations may be less likely to be driven by extrinsic factors and more likely to be motivated by intrinsic factors (Benz, 2005; Handy \& Katz, 1998; Bassous, 2015). Intrinsic motivation includes; job content, personal growth, responsibility and advancement (Lee \& Wilkins, 2011). In their study of nonprofit organizations in Western Australia, Colleran et al., (2010), found that four out of five retention motivators were intrinsic. Intrinsic motivation is also highly correlated with faith-based non-profit organizations (Netting et al., 2006).

The distinction and interrelatedness of extrinsic and intrinsic motivation while constituting one of the most researched aspects of motivation, also represent one of the most complex (Wenger \& Yarbrough, 2005). In fact, it has been suggested that the relationship between intrinsic and extrinsic motivation is far more intricate that commonly understood (Park \& Ward, 2012). Not only has the di- 
chotomy itself come under question, but Deci \& Ryan (2000) suggest that the classification is insufficient to account for the entire spectrum of human motivation.

The effectiveness of mission statements in fostering positive attitudes, driving job satisfaction and enhancing intention to stay have been discussed in the literature (Braun, Wesche, Frey, Weisweiler, \& Peus, 2012). The mission statement has been described by the authors as consisting of three components: a visionary component with emotional content, its raison d'etre including tasks and duties and thirdly, the mission statement as pertaining to the organization's philosophy and values.

\subsection{Motivation: Job Satisfaction}

Job satisfaction is considered to be one of the most highly investigated topics in organizational research as it relates to the motivation and retention of employees (Van Der Westhuizen et al., 2011). Although the link between satisfaction and retention has been established in the literature (Freund, 2008; Omoto \& Snyder, 1995), other studies have failed to find a unified relationship (Penner \& Finkelstein, 1998). In nonprofit organizations, intrinsic satisfaction has been found to serve as an important factor in employee retention (Benz, 2005). Intrinsic rewards were related to a relatively low turnover rate in a study by Colleran et al. (2010). Research has found that employees who move from for-profit organizations to non-profits are more intrinsically motivated. In exchange for higher job satisfaction, flexibility, and improved relationships they are willing to accept lesser equivalent wages (Becchetti, Castriola, \& Depedri, 2014). In a study of the non-profit sector in Western Australia, employees ranked the following retention and motivating factors: passion, work-life-balance, career development, interesting job tasks (Colleran et al., 2010).

\subsection{Motivation: Spirituality}

A study by Bassous (2015) indicates that the motivation of faith-based employees is closely related to personal faith. For many of these workers, their choice of employment is motivated by a higher Calling. A Call is described as an exhortation received from the divine; either through spiritual impartation or human agency, and it relates to life choices.

Spirituality has been described as a significant and irreducible human motivation in a study by Pargament (2013). The definition and distinction between spirituality and religion remains an ongoing conversation and an in-depth discussion falls beyond the scope of this inquiry. It is necessary to acknowledge, however, that the terms remain interchangeable in some areas of the literature which stresses their commonalities. Hicks (2003) proposes that the definition of spirituality is considered too broad to be coherent. In response to this, this inquiry offers a working definition of spirituality in specific context: Spirituality is a connection to God through personal relationship. It constitutes dynamic personal 
growth based on a tradition of faith beliefs shared in community which finds expression in the divine purpose of altruistic service and love for others (Erasmus et al., 2021). In his study, Pargament (2013) notes that psychology generally has neglected Spirituality as a motive in and of itself. By choosing to situate the inquiry within a faith-based environment, this study hopes to give more attention to this phenomenon.

\subsection{Spirituality and Religion in the Workplace (SRW)}

The study of spirituality and religion in the workplace is described as an emerging area of inquiry (Benefiel, Fry, \& Geigle, 2014). SRW has its roots in philosophy and religion but it is suggested that the field of psychology of religion and spirituality has much to offer that can be applied to the workplace. The essential elements of SRW include: the acknowledgement that employees have an inner life; meaningful work; creating a company culture that fosters spiritual growth. Importantly too it incorporates the concept of spiritual leadership developed by Fry (2003) which was extended to include the importance of inner life and life satisfaction.

\subsection{Conclusion}

Although there is consensus that the high turnover rate in non-profit organizations in general has led to the consideration of turnover as a top priority (Kang, Hugh, Cho, \& Auh, 2015), little work has been done on why employees choose one sector rather than another (Colleran et al., 2010). There is a sparcity too of qualitative approach in the field.

\section{Methodology}

The ontological position adopted by this research follows that a study of the motivation of accounting staff in an Australian faith-based non-profit system, is principally about the perception of individual employees of the factors that influence their decision to join, remain or leave current job appointments in this context. Perceptions gained directly from the data in respect of individual employee motivation have the potential of furthering understanding of interpersonal and organizational factors impacting the experience of accounting staff within such an organization. This concurs with a pragmatic orientation which says, "people always interpret events from a situated and complexly principled point of view" (Star, 2007: p. 88).

A qualitative approach was deemed the best match for this inquiry as it is a research orientation which explores social and human problems by building a complex, holistic picture through word analysis and detailed views of participants in a natural setting (Creswell, 1998). A grounded theory study was selected based generally on the approach of Strauss and Corbin (1990) which follows an inductive approach, but which does not preclude an abductive research logic (Reichertz, 2007). Grounded theory is defined by Creswell (2009: p. 229) as; "a 
qualitative strategy in which the researcher derives a general abstract theory of a process, action, or interaction grounded in the views of the participants of the study". In terms of this approach, theory is discovered through the systematic collection and simultaneous analysis of data pertaining to the field of inquiry. Contrary to simplistic induction, the inquiry acknowledges the role of pre-existing theory in sensitizing the researcher to frame relevant interview questions. Due process was followed to validate the interpretation of the data by allowing negative and contrary perceptions to be included. In this study the views of dissatisfied, former employees were incorporated. To address potential bias, one researcher was not a member of the church organization studied. The other researcher, who is a member, was chosen for the depth of insight provided into the culture and traditions of the organization which made for an authentic contextual reference.

Semi-structured interviews were conducted with 17 experienced accounting staff within the faith-based organization in New South Wales, Australia. The sample consisted of 10 current and 7 former employees of the organization. Early interviews were audiotaped and transcribed verbatim on to a word processor for coding and analysis. Initial face-to-face interviews were conducted on site. The interviewing process was interrupted by the advent of the Covid-19 pandemic. Final interviews were based on either telephonic or online conversation. The interviews were conducted mainly in the offices of the Treasury departments from November 2019 to April 2021. A demographic section was followed by open questions about individual perception. Participants were asked questions such as: What made you choose to work in a faith-based non-profit organization? Would you consider leaving if offered substantially higher financial incentives?

The collection and analysis of the data occurred simultaneously in line with a grounded theory approach. Saturation was deemed to have been reached when no further ideas or properties emerged from succeeding interviews (Sheppard, 2004). Analysis proceeded initially with a line-by-line coding for in vivo codes (Glaser \& Strauss, 2008). By constant comparison, principal categories, grounded in the empirical data, were developed through theoretical sensitivity and not forced from the data (Dey, 2007). Categories emerged with two theoretical properties: a set of sub-categories and the relationship between the different categories (Kelle, 2007). From these categories a substantive theory was developed. A substantive theory is differentiated from formal theory in that the former is directed to a specific sociological context and does not aim at generalizability while the latter is applicable to broad social concepts with general applicability (Lempert, 2007).

A purposeful sampling method was employed. "A purposeful sample is one that provides a clear criterion or rationale for the selection of participants, or places to observe, or events, that relates to the research questions" (Ezzy, 2002: p. 74). The chief criteria for eligibility were that participants have experience of the research phenomenon and were willing to participate in conversation. The Trea- 
sury department was selected specifically for its representation of diversity in terms of gender, age, culture and disability. Views of both management and employees were included in the interview process. A few had previous experience in corporate and state organizations. Ethics approval for this study was granted by the Avondale Human Research Ethics Committee.

\section{Participants}

Potential participants were located through the central administration office of the organization in Sydney. Managers of the treasury departments were then contacted by telephone and invited to participate in the study. The managers acted as gatekeepers to introduce researchers to potential interviewees in the organization. Those who registered interest and who met the criteria were issued with an information sheet which included a section on participant rights including a privacy clause and the right to opt out of the process at any stage.

A total of 17 participants who met the criteria outlined previously participated using a semi-structured interviewing process. As the total number of employees in these particular departments was small, the number of interviews is more than representative. The sample represented male participants $(n=8)$ and female $(n=9)$. Most of the participants were married $(n=12)$ but there were also single and divorced participants. The ages of the participants ranged from 25 years to 53 years. The participants were representative of Australian, New Zealand, Chinese, Filipino and South American cultural backgrounds. The sample consisted of current and former accounting clerks, accountants at various levels, and auditing staff. All 17 participants held Bachelor degrees, mostly with accounting majors. The picture that emerges is of a well-qualified cohort of treasury accounting staff.

\section{Findings}

From an analysis of the data three core motivation categories, relating directly to the research phenomena are identified. They are: Purpose, Progress, Proximity. Findings from the analysis indicate that the categories are multifaceted and often interrelated but for explication they are discussed separately and in no hierarchical order.

\subsection{Purpose}

Purpose is described in the literature as relating to social and economic considerations in addition to psychological forces (Rey \& Malbasic, 2019). A sense of Purpose was identified as a core motivation category for this sample of accountants. In this study the phenomenon is characterized essentially by mission congruence, contribution, commitment and culture. These findings address the challenge of identifying purpose that fosters emotional commitment and multiple objectives and which potentially would be limited by adopting linear models to measure a multifaceted phenomenon. 


\subsubsection{Mission Congruence}

Participants in this study indicate that choosing to work in a faith-based nonprofit organization was strongly influenced by the congruence of individual motivations with the values and philosophy of the organization. Being able to combine a career with their altruistic values featured prominently in their perception of being satisfied with their position. An interesting perspective is given by a young senior accountant who had left the government sector for the non-profit sector:

I think for me it's never been about remuneration. It's always been about what I can contribute to my work and the people round me which is one of the reasons I left. I thought working for a government organization with the purpose of keeping the environment clean was a good bigger cause and I quite enjoyed working there until it got to the point where my beliefs and values and that of the company did not quite match up anymore.

Participants ascribed their strong organizational value alignment to a faith-based background. The generally accepted mantra of non-profit organizations, "people are more important than money", was congruent with the values they had grown up with. These findings concurred with Bielefeld and Cleveland (2013) that individuals with religious backgrounds are attracted to the mission statements of organizations.

In this study accounting staff chose to work for a faith-based organization to be part of the missionary cause. A mature female accountant said:

It does the heart good to know you are contributing to the heart of the mission of the place. You are making a difference in life in some ways and particularly in the role I'm in.

Non-alignment of personal and organizational values among former employees had resulted in feeling demotivated. Conflicting values lead to a decision to leave.

The mission statement of the non-profit was perceived to be embedded in that of the church organization to which they belonged.

\subsubsection{Contribution}

The organization's missionary declaration, "we invest in others", connected individuals to a bigger picture. Participants felt their work was meaningful when they perceived that their service was in the interest of others and contributed to making a difference in the lives of others. One female accountant who left a for-profit organization said:

The purpose of this organization [non-profit] to support members of our church community in financially managing their lifestyle is important to me-I liked that we can be there to help people with that.

A definite link between having a sense of contributing to the good of others and satisfaction with employment was identified. One manager said:

It's not just about lining someone else's pocket. 
Although participants acknowledged that they were not traditional frontline workers like pastors and missionaries, they still felt they were making a difference and contributing to the mission of the organization and the church.

One accountant in the Newcastle department commented:

It's rewarding when your role means interacting with the people you are supporting. Feels like you are in the frontline of making a difference. In corporate areas there are less interactions with clients and therefore you feel more removed.

Conversely, individuals who felt they were not making a contribution, felt no sense of purpose. As one interviewee said:

When it becomes just a job, it doesn't feel like you are making a difference.

\subsubsection{Culture}

A faith-based organizational culture emerged as a strong factor impacting satisfaction with employment. This culture was described as one which embraced spiritual ideals, where individuals were valued and respected, trust existed, decision-making was based on faith-based values, diversity was upheld and support from leadership and team existed at all levels. When this was perceived, it drove a strong connection between personal values and the culture of the organization. One participant said:

I feel like I am at home.

Cultural diversity is strongly represented in this organization. Employees included Australian, New Zealand, South American, Tongan, Filipino and Asian workers. One line manager said that purposefully building an organizational culture of respect and value helped to unite members from different cultures. A traditional stance of "this is how you do it and that is that" did not promote positive motivation in a diverse team. A culture of respect and value was built on individual relationships. He said:

Building relationships is most time consuming, but vital for creating respect and value.

Potentially, there could be instances where traditional cultural values and organizational values appeared conflicting. An example was gender ranking in some Pacific Island cultures, and collective versus individual decision-making processes. According to managers, these differences may be overarched by creating a strong organizational culture of value and respect.

According to participants, a strong team culture of support and shared values contributed to a positive working experience. An attitude of, "we are all in this together", endorsed feelings of confidence and trust. One younger accountant described it as follows:

If we succeed, we all succeed. If we fail, we all fail. If anyone drops the ball, we will all help carry it on. 
In this faith-based context, trust was experienced as multi-dimensional phenomena. Trust was perceived as a relational dynamic that took time to develop. If there was no faith in team leaders, individuals felt demotivated. Trust and integrity were seen as significant for maintaining transparency and accountability for stakeholders and ultimately for being honest managers of God's money. A strong link between trust and autonomy fostered satisfaction with working experience as discussed in the following section.

\subsection{Progress}

The concept of Progress, with individual growth and learning as a principal element, emerged as a significant motivation for this sample of accountants. Even in cases where individuals expressed a primary commitment to organizational and church mission, a sense of stagnation could potentially override the commitment and result in exit intention.

\subsubsection{Growth and Development}

A perceived lack of opportunity to grow and develop constituted the single most important factor impacting intention to leave in this study. Although smaller organizations were perceived to offer swifter career progression, there was a definite perception of a ceiling potentially spelling stagnation and demotivation. A former assistant manager said:

It was a dead-end being in a small organization.

Opportunity to grow and develop was restricted by the size of the organization and by budget limitations according to participants. A former employee said that although she had been encouraged to learn new things, a small organization meant there was limited opportunity to go any further.

Several participants said that a deciding driver in leaving would be the perception of a lack of a clear career pathway. The following statement is representative of most of the sample:

It may get to a state where I would have to think about moving on for my own growth.

In both departments, leaders and managers were aware of these sentiments. As leaders they were committed to helping employees to develop professionally and sought to encourage training in areas of interest. These were limited, however, by budget restrictions. One line manager outlined his philosophy:

Point being that they should be able to look back at this organization as a good place to have been employed.

\subsubsection{Mentorship}

Individual progress both on a personal and professional level was positively motivated by the input of mentors. Interestingly, personal mentorship was preferred to Human Resource assistance. According to this sample, mentors should have 
the following qualities: be humble, trustworthy, have insight into cultural differences, be knowledgeable, accessible and empowering. One participant with a disability said that the ongoing influence of a personal mentor at the organization was a deciding motivator in intention to remain. Both formal and informal mentoring were regarded as contributing to satisfaction with current employment. Formal mentorship was initiated by the organization while informal mentorship frequently arose spontaneously. The principal emphasis in both cases was on relationship. Regardless of form, mentorship was associated with both career development and psycho-supportive functions and both forms were seen as promoting opportunity for growth and development.

\subsubsection{Autonomy}

Findings from an analysis of the data showed a definite link between autonomy and job satisfaction in this study. Autonomy for these participants was related to confidence and trust. Satisfied employees were trusted with projects without being micro-managed and felt confident about approaching direct management with new ideas. They felt confident about motivating for new ideas and felt that the line manager, "always has our voice".

One participant described the experience as one which:

Allowed me freedom to do work, knowing there's a confidence that it will

be done well and within the best possible time. Not over-managed.

Direct managers in the department acknowledged the importance of an autonomous management practice and its role in fostering retention. The general view from participants in this study was that although autonomy was consciously implemented at first line management level, it was stifled by more hierarchical "forces higher up". particularly as it pertained to planning and development. Consequently, as one participant put it:

It feels like our suggestions don't carry much weight higher up.

These sentiments were considered demotivating and resulted in employees feeling devalued.

\subsubsection{Leadership Style}

Opportunity to grow and develop was linked by this sample to leadership style. A transformative style and servant leadership approach were regarded as enhancing opportunity for personal learning and growing. An interesting and unexpected result was the view that these leadership styles were generally experienced at managerial level. This suggests that employees are positively motivated by leadership style regardless of the level of position. When this style is perceived to be supportive, transparent and encouraging of growth and development, it fosters a sense of satisfaction with work experience. A sense of value and well-being was further imputed by leaders who provided input into the spiritual growth of employees.

Leaders who adopted a servant leadership style said it was based on the Bibli- 
cal model of Jesus where every individual was valued. In this model, people have intrinsic value irrespective of their academic qualifications or cultural background. The aim of leadership was to nurture and grow every individual to their full potential. These elements of leadership are characteristic of Greenleaf's servant leadership model (Greenleaf, 1998) and suggest an intuitive alignment with this context. For this sample, feeling valued included positive and timely feedback from leadership, intrinsic and extrinsic reward and experiencing a feeling of connection to co-workers, leaders and the organization.

In practice, however, there appeared to be some disparity between support for servant leadership style in principle and dissatisfaction with aspects of the practical application. Some participants felt the church culture of grace could result in a leniency of organizational management practice potentially leading to a failure in dealing with underperformance and decisive decision-taking. One participant said:

That's the thing about working for the church. Sometimes we extend too much grace and we let things slide. People who don't make the grade, we just shove them around, making them someone else's problem.

In situations where team members did not pull their weight, the resulting additional responsibility fell on the shoulders of other members. The added workload was demotivating, increasing work pressure and consequently leading to dissatisfaction with employment and potential burnout.

\subsubsection{Burnout}

Increased workload resulting from staff under performance issues and insufficient resources were shown in this study to relate to demotivation and potential turnover intention. A perception of rising expectations coupled with increased workload was the principal factors relating to potential burnout. This was perhaps even more evident at senior level. Former employees with near burnout described increased workload, complexity of roles, staff turnover, inconsistent management practice and insufficient resources.

The role of expectations as a multi-faceted phenomena and its contribution to potential burnout in faith-based accounting practice is mentioned here but needs further exploration. In some cases, there was additional stress of experiencing blurred boundaries between work and church life where church felt like "another day at the office".

Managers were aware of this phenomenon. Some managers had themselves been close to burnout and were able to use their experience to adopt measures to protect staff from burnout. One manager said:

I keep telling myself I have to walk the talk as well. I always tell my staff: "your personal health is very important". Everyone is different and we must make sure their mental health is catered for.

Another manager described the added stress that work-from-home initially 
caused employees:

2020 has been very hard. Initially there were issues in respect of work from home. It was stressful when staff were not able to access our system from home. This is fixed now but we still meet once a week to help with work or personal issues. We try to go out of our way to help.

\subsubsection{Remuneration}

Remuneration is regarded as an extrinsic reward and its role in creating satisfaction with employment and potentially turnover intent has been discussed earlier. An analysis of the data showed that participants viewed entry level wage at a non-profit as comparative if not better than that at many corporates. As levels rise, however, there is significant disparity in salary scales.

Most participants reported mission alignment (putting people ahead of profits) as a strong initial attraction to non-profit employment. As one participant said:

Money is not the driver. I am motivated by bringing value. I took a big pay cut for the current position and work a zillion times harder.

This result compares with the view of Becchetti, Castriota \& Depedri (2014) that individuals who are more intrinsically motivated will change jobs even if it means lower salary scales. It would appear, however, that although this stance is a luxury that can be expounded by more mature employees and even a few single individuals, pragmatic considerations such as the addition of family responsibilities may require a different response. In most instances the decision to leave the organization was far more complex than just financial concerns. A female accountant refers to this complexity:

Money was not the primary incentive for change. There are a lot more things involved in making that decision.

Several employees with families said that family considerations currently took precedence and that despite a strong mission orientation, they would be tempted to leave if offered tempting financial incentives. This result concurs with the view of Brown and Yoshioka (2003) that mission congruence may not be sufficient to retain employees.

\subsection{Proximity}

The concept of proximity emerged as an important motivator in decision to stay. Proximity included the important elements of time and space. These factors in turn were directly related to work-life balance which has been widely reported to have links to job satisfaction

Analysis of the data showed a strong relationship between work-life balance and the elements of place and time. A former female employee described her experience:

I struggled with work-life balance due to all the travelling I was doing. It 
was a big factor in me leaving.

Heavy workloads and time away from home and family were regarded as negatively impacting work-life balance. A former employee expressed it as follows:

They are expecting a lot of you in terms of your work-life and your balance is crushed but you are not compensated in the same way as in the corporate sector.

Personal time with family, community contact and pursuit of hobbies were impacted directly by long hours spent at work as well as time spent commuting to work. The extent of this time was becoming a calculated factor with the onset of the restrictions of the covid-19 pandemic which resulted in employees working from home. They were beginning to realize how much time was saved by not having to commute to work. As this study was conducted at the onset of the pandemic, the full impact of work-from-home in this context needs further inquiry.

Management indicated an awareness of the need to address work-life balance for employees and that fostering a holistic lifestyle was convergent with the values of the employing church organization. Employees were encouraged to stick to working hours where possible, limit overtime and work efficiently and effectively to maintain boundaries. One manager who had experienced near burn-out said:

As a leader, you have to walk the talk. Structure the day purposefully to enable quality time with family.

Participants in this study who considered their work-life balance to be positive were of the view that proximity of workplace played a significant role in maintaining this balance. Being close to home enabled employees to save substantial travel time, work in with school day schedules, attend sport and hobby events and be easily accessible in case of home emergency. They considered these elements to be conducive to mental health and sustainability. In one instance where an employee with visual impairment was able to walk to work and back independently, satisfaction with work was linked directly to proximity and flexibility. In an interview he said:

I live five minutes away. It's good because I don't drive. So I am able to walk home even for lunch with my wife and daughter. Given that I don't have any travel time, I can be at home as much as possible.

Participants rated flexibility of working hours highly when deciding to choose a faith-based non-profit organization as a place of work. Women with school-age children who were given the option of flexible starting and finishing hours said that the ability to drop and collect children from school while finishing the day's work off at home contributed significantly to their satisfaction with employment. A female accountant endorsed this view:

Flexibility of hours, being near home, is really good. 
Most of the participants rated the organization's practice of half day Friday and the nine-day fortnight as highly desirable and as contributing to work-life balance and consequently increased employment satisfaction. It is clear from these findings that a sense of well-being was increased when employees experienced enough flexibility in their working week to make place and time positive elements in their lifestyle.

\section{Substantive Theory}

Data analysis and a consideration of the findings of this study have led to the development of a substantive theory relating to the research phenomena. Substantive theory, as has been noted, should be differentiated from formal theory in that it is directed to a specific sociological context at a point in time. For this context the following is offered:

Principal theoretical concepts of Purpose, Progress, Proximity, operationalized through the dynamic elements of Connection, Growth and Balance, have the potential to positively promote the retention of faith-based accountants in a nonprofit organization.

One of the objectives of this study is to demonstrate the practical application of theory to everyday working practice. The inclusion of the comprehensive list of recommendations for management practice developed from the findings, falls beyond the scope of this study. The following examples are selected as an illustration of the application of identified theoretical principles:

Leaders should be aware that both intrinsic and extrinsic rewards increase a sense of feeling valued. Altruistic motivation is not sufficient to prevent turnover resulting from the attraction of significant pay increases from for-profit organizations.

Fostering a sense of connection at all levels of the organization is conducive to satisfaction with employment.

It is suggested that the opportunity for growth and development be maximized within career trajectories despite a potential loss of employees.

A culture of diversity in which a variety of traditions is acknowledged within an umbrella approach of respect and value, is conducive to satisfaction with employment

A faith-based Call is a strong motivator but not sufficient to retain employees who regard their Call as relating to a bigger picture which may extend beyond the organization.

\section{Limitations}

A single organization in a slice in time inquiry has obvious limitations in terms of generalizability. Despite the limitation, certain inferences particularly those pertaining to general non-profit management practice may well be transferable if tested in further study.

The current study was conducted as a cross-sectional exploration and it is ac- 
knowledged that motivational drives may alter with time as hinted at in the study. Longitudinal studies may provide more insight into the changing motivational drives of individuals in specific context. The impact of covid-19 restrictions on the work experience and perceptions of employees in the non-profit sector await future inquiry. Particular attention should be given to factors promoting satisfaction in a work-from-home experience. Even prior to the impact of covid-19, proximity emerged as a significant factor in the decision to remain. Future study should examine the potential difference in gender and age perception in respect of proximity.

Interesting insights were gained into the role of cultural diversity. This study, however, is limited to a Christian perspective. Future investigations should include faith diversity in different contexts. The current inquiry highlighted the role of mentorship in fostering satisfaction with employment. This was limited to male mentors. The role of female mentors in accounting fields would be a valuable contribution to the conversation.

\section{Discussion}

The study began by asking the question: why would professional accountants choose to work in non-profit organizations for lesser pay and opportunity? Although the sentence structure is simple, the answers proved far from simple. It was concluded with Vallerand (2012) that motivational processes are multi-determined. The lived experience of multi-faceted employees cannot be divorced from their personal beliefs and values nor from their cultural context. This finding complements the view of Perry, Jeffrey, Brudney, Coursey \& Littlepage (2008) that individuals who cite spirituality as a principal motivation do not separate their lives into categories of religion, personal life and helping activities.

Findings from the data indicated that accountants in specific context were principally motivated to work in the current organization if they experienced connection to the three principal categories of Purpose, Progress and Proximity. In line with Lewin (1946) that there is nothing so practical as good theory, the primary elements of connection, growth and balance offer practical application for non-profit management practice. A summary recommendation cautions against transferring general human resource management models to specific business contexts in the third sector. Findings from the current study reiterate that nonprofit environments differ from that of other sectors. Leaders and managers of non-profit organizations who desire to retain professional talent are advised to ensure that individuals retain a sense of connection to the primary motivating categories in specific context.

Spirituality as a distinctive motivating factor for this sample of accountants emerged strongly from participating interviews. This concurs with the view of Pargament (2013) that the spiritual function is the most salient motivating factor for faith-based individuals. Findings agree with Lee et al. (2003) that spiritual sa- 
tisfaction was a significant predictor of life satisfaction. Although the Call is a strong motivator for faith-based employees, it is insufficient of itself to retain employees in a single organization.

The significance of value congruence for employee retention has been demonstrated in former studies. In the current study, the concept of mission congruence implies a wider perception which incorporates vision but is extended to a worldwide mission of serving God and people. The strong association between mission as an incentive and workers motivation level was also found by Bassous (2015).

The current study agrees that intrinsic work benefits, which include promoting missionary goals, motivate intention to stay in non-profit organizations (Benz, 2005) potentially reducing turnover intention (Perry \& Wise, 1990). Although significant, mission congruence alone was not sufficient to ensure the retention of professional accountants in this context. This is similar to the view of Kim \& Lee (2007) and Brown \& Yoshioka (2003) who call for further insight into individual perception. Individual views in the current study showed that value disconnect results in dissatisfaction with employment and ended with decision to leave. Value disconnect from organizations whether for-profit or non-profit was significant enough to motivate decision to leave.

The promotion of a culture where individual diversity was valued enhanced satisfaction with employment. In the literature review it was noted that job satisfaction was considered in relation to intrinsic and extrinsic motivation (Bektas, 2017). It was also found that intrinsic motivation was closely linked to personal faith for this sample. This is in accordance with the finding of Bassous (2015).

The importance of intrinsic incentives such as work-life balance, and professional development opportunities were identified as crucial factors in fostering intention to remain. Similar factors were identified by Colleran et al. (2010) in a study of non-profits in Western Australia. In this study intrinsic motivations, which were aligned with value-based reward, featured prominently in promoting job satisfaction.

Despite the relatively high level of satisfaction experienced by most of the participants in this study, employees with career aspirations and family commitments indicated they would be attracted to other sectors by the lure of significant increase in salary and career development opportunities. This means that despite the intrinsic motivation that connects professional accountants to non-profit organizations, managers and leaders cannot remain complacent about salary structure. Change in personal circumstances may well impact the pre-eminence of intrinsic factors. Finding from this inquiry adds insights which argue against a clear-cut dichotomy of intrinsic and extrinsic motivators. It brings the current inquiry into line with the suggestion of Deci \& Ryan (2000) that the intrinsic/extrinsic dichotomy is insufficient to account for the full spectrum of motivation in personal lives. Complexity of life experience suggests a complex com- 
bination of intrinsic/extrinsic motivating factors.

Participants in this study expressed the opinion that leadership style had a direct impact on their motivation to stay with the organization. This concurs with Bassous (2015) who found that more than $80 \%$ of participants said that leadership influenced motivation. The current study indicated that transformative, servant leadership style was perceived to promote autonomy, opportunity for growth and development, value congruence and a positive culture of value and trust. These factors were shown to promote satisfaction with current work position. This style of leadership which included mentorship was characterized by interpersonal connection. It may be experienced at all levels of management and not limited to senior leadership. Hierarchical management practice, however, was seen to thwart autonomy and increase a sense of disconnection which resulted in dissatisfaction. Although transformative, leadership style was preferred, workers expected management to implement strategies for dealing with underperforming co-workers.

With the advent of covid-19, accounting staff had started working from home. Although the views in this study were captured in the early stages of the impact, it appears that the advantages of time and space saved by not commuting to work increased the prominence given to flexibility as a principal consideration for intention to remain. Flexibility was identified as a primary promoter of work engagement in studies by Brown \& Yoshioka (2003) and Colleran et al. (2010). As flexibility was linked to work-life balance in this study it would be interesting to explore the relationship between the flexibility offered by work-from-home scenarios and the impact on work-life balance in a covid-19 environment in this context.

\section{Concluding Remarks}

The critical challenge of retaining professional workers in a covid-19 business climate, where non-profit organizations are expected to be increasingly impacted by declining donations and limited resources, makes an inquiry into retention motivation vital. The substantive theory furthers insight into individual motivation while offering practical recommendations to non-profit management practice. Given the uncertainty of the full impact of pandemic restrictions on the business community and the potential for disconnection at all levels of society, non-profit management with the ability to foster connection at all levels of the motivation categories, presents a positive opportunity to retain those who stay for less pay.

\section{Conflicts of Interest}

The authors declare no conflicts of interest regarding the publication of this paper.

\section{References}

Adhikari, A. (2009). Factors Affecting Employee Attrition: A Multiple Regression Approach. Journal of Management Research, 8, 38-43. 
Bassous, M. (2015). What Are the Factors That Affect Worker Motivation in Faith-Based Non-Profit Organizations? Voluntas, 26, 355-381.

https://doi.org/10.1007/s11266-013-9420-3

Becchetti, L., Castriota, S., \& Depedri, S. (2014). Working in the For-Profit versus Nonfor-Profit Sector: What Difference Does It Make? An Inquiry on Preferences of Voluntary and Involuntary Movers. Industrial and Corporate Change, 23, 1087-1120. https://doi.org/10.1093/icc/dtt044

Bektas, C. (2017). Explanation of Intrinsic and Extrinsic Job Satisfaction via Mirror Model. Business and Management Studies: An International Journal, 5, 627-639. https://doi.org/10.15295/bmij.v5i3.118

Benefiel, M., Fry, L. W., \& Geigle, D. (2014). Spirituality and Religion in the Workplace: History, Theory, and Research. Psychology of Religion and Spirituality, 6, 175-187. https://doi.org/10.1037/a0036597

Benz, M. (2005). Not for the Profit, But for the Satisfaction? Evidence on Worker Well-Being in Non-Profit Firms. Kyklos, 58, 155-176. https://doi.org/10.1111/j.0023-5962.2005.00283.x

Bielefeld, W., \& Cleveland, W. S. (2013). Defining Faith-Based Organizations and Understanding Them through Research. Non-profit and Voluntrary Sector Quarterly, 42, 442 467. https://doi.org/10.1177/0899764013484090

Brandel, G. A. (2002). Non-Profit Salary Trends. The CPA Journal, 72, 16.

Braun, S., Wesche, J. S., Frey, D., Weisweiler, S., \& Peus, C. (2012). Effectiveness of Mission Statements in Organizations-A Review. Journal of Management and Organization, 18, 430-444. https://doi.org/10.1017/S1833367200000687

Briggs, E., Peterson, M., \& Gregory, G. (2010). Toward a Better Understanding of Volunteering for Non-Profit Organizations: Explaining Volunteers' Pro-Social Attitudes. Journal of Macromarketing, 30, 61-76. https://doi.org/10.1177/0276146709352220

Brown, W. A., \& Yoshioka, C. F. (2003). Mission Attachment and Satisfaction as Factors in Employee Retention. Non-Profit Management and Leadership, 14, 5-18. https://doi.org/10.1002/nml.18

Brundage, H., \& Koziel, M. (2010). Retaining Top Talent Still a Requirement for Firms: Focus on People Now to Keep Turnover Costs down When the Economy Improves. Journal of Accountancy, 209, 2159.

Christeen, G. (2015). Retaining Professional Workers: What Makes Them Stay? Employee Relations; Bradford, 37, 102-121. https://doi.org/10.1108/ER-10-2013-0151

Christensen, C. M. (2016). The Innovator's Dilemma: When New Technologies Cause Great Firms to Fail (Management of Innovation and Change) (Illustrated ed.). Harvard Business Review Press.

Cnaan, R. A., \& Curtis, D. W. (2013). Religious Congregations as Voluntary Associations: An Overview. Non-Profit and Voluntary Sector Quarterly, 42, 7-33. https://doi.org/10.1177/0899764012460730

Colleran, N., Gilchrist, D. J., \& Morris, L. (2010) Staff Retention Factors in the Non-Profit Sector: An Examination of a West Australian Community Organization. Third Sector Review, 16, 43-60.

Creswell, J. W. (1998). Qualitative Inquiry and Research Design: Choosing among Five Traditions. Sage.

Creswell, J. W. (2009). Research Design; Qualitative, Quantitative, and Mixed Methods Approaches. Sage.

Deci, E. L., \& Ryan, R. M. (2000). The "What" and the "Why" of Goal Pursuits. Human 
Needs and the Self Determination of Behavior in Psychological Inquiry, 11, 227-268. https://doi.org/10.1207/S15327965PLI1104_01

Deitrick, L., Tinker, T., Young, E., Strawser, C. C., Meschen, C., Menriques, N., \& Beatty, B. (2020). Non-profit Response to Covid-19. Non-Profit Sector Issues and Trends, 3, $1-7$.

Dey, I. (2007). Grounding Categories. In A. Bryant, \& K. Charmaz (Eds.), The Sage Handbook of Grounded Theory (pp. 167-189). Sage.

Erasmus, B., Morey, P. J., Williams, P., \& Manners, B. (2021). Shifting Gears: An Exploratory Study of Factors Impacting the Well-Being of Retired Clergy in Australia and New Zealand. Journal of Religion, Spirituality and Aging. https://doi.org/10.1080/15528030.2021.1913467

Ezzy, D. (2002). Qualitative Analysis. Allen \& Unwin.

Frank, R. H. (1993). What Price the Moral Ground? Cornell University.

Freund, A. (2008). Commitment and Job Satisfaction as Predictors of Turnover Intentions amongst Welfare Workers. Administration in Social Work, 29, 5-21. https://doi.org/10.1300/J147v29n02_02

Fry, L. W. (2003). Toward a Theory of Spiritual Leadership. The Leadership Quarterly, 14, 693-727. https://doi.org/10.1016/j.leaqua.2003.09.001

Gagne, M., \& Deci, E. (2005). Self-Determination Theory and Work Motivation. Journal of Organizational Behavior, 26, 331-362. https://doi.org/10.1002/job.322

Ghosh, P., et al. (2013). Who Stays with You? Factors Predicting Employee Intention to Stay. International Journal of Organizational Analysis, 21, 288-312. https://doi.org/10.1108/IJOA-Sep-2011-0511

Glaser, B. G., \& Strauss, A. L. (2008). The Discovery of Grounded Theory: Strategies for Qualitative Research. Rutgers.

Greenleaf, R. K. (1998). The Power of Servant Leadership. Berrett-Koehler Pubishers.

Handy, F., \& Katz, E. (1998). The Wage Differential between Non-Profit Institutions and Corporations; Getting More or Paying Less? Journal of Comparative Economics, 26, 246-261. https://doi.org/10.1006/jcec.1998.1520

Helmig, B., Jegers, M., \& Lapsley, I. (2004). Challenges in Managing Non-Profit Organizations: A Research Overview. Voluntas, 15, 101-116. https://doi.org/10.1023/B:VOLU.0000033176.34018.75

Hicks, D. A. (2003). Religion and the Workplace: Pluralism, Spirituality, Leadership. Cambridge University Press. https://doi.org/10.1017/CBO9780511615474

Holland, P., Sheehan, C., \& De Cieri, H. (2007). Attracting and Retaining Talent: Exploring Human Resources Development Trends in Australia. Human Resource Development International, 10, 247-262. https://doi.org/10.1080/13678860701515158

Kang, C., Huh, S., Cho, S., \& Auh, E. Y. (2015). Turnover and Retention: The Korean College Graduates' Experience. Non-Profit and Voluntary Sector Quarterly, 44, 641-664. https://doi.org/10.1177/0899764014553032

Kelle, U. (2007). The Development of Categories: Different Approaches in Grounded Theory. In A. Bryant, \& K. Charmaz (Eds.), The Sage Handbook of Grounded Theory (pp. 191213). Sage. https://doi.org/10.4135/9781848607941.n9

Keys, J. (2017). Ten HBR Challenges for NFPs. http://thirdsector.com.au/89143-2

Kim, S. E., \& Lee, J. W. (2007). Is Mission Attachment an Effective Management Tool for Employee Retention? An Empirical Analysis of a Non-Profit Human Services Agency. Review of Public Personnel Administration, 27, 227-248. 
https://doi.org/10.1177/0734371X06295791

Kirsch, C. (2007). Loyalty and Disengagement-Taming the Retention Monster. Keeping Good Companies, 59, 557-565.

Lee, D., Sirgy, M. J., Efraty, D., \& Siegel, P. (2003). A Study of Quality of Life, Spiritual Well-Being, and Life Satisfaction. In R. A. Giacalone, \& R. A. Jurkiewicz (Eds.), Handbook of Workplace Spirituality and Organizational Performance (pp. 209-221). M.E. Sharpe.

Lee, Y. J., \& Wilkins, V. M. (2011). More Similarities or More Differences? Comparing Public and Non-Profit Managers' Job Motivations. Public Administration Review, 71, 45-56. https://doi.org/10.1111/j.1540-6210.2010.02305.x

Leete, L. (2000). Wage Equity and Employee Motivation in Non-Profit and For-Profit Organizations. Journal of Economic Behaviour and Organization, 43, 423-446. https://doi.org/10.1016/S0167-2681(00)00129-3

Lempert, L. B. (2007). Asking Questions of the Data: Memo Writing in the Grounded Theory Tradition. In A. Bryant, \& K. Charmaz (Eds.), The Sage Handbook of Grounded Theory (pp. 245-264). Sage. https://doi.org/10.4135/9781848607941.n12

Lewin, K. (1946). Action Research and Minority Problems. Journal of Social Issues, 2, 34-46. https://doi.org/10.1111/j.1540-4560.1946.tb02295.x

Meneghetti, M. M. (1995). Motivating People to Volunteer Their Services. John Wiley \& Sons, Inc.

Moynihan, D. P., \& Pandey, S. K. (2008). The Ties That Bind: Social Networks, PersonOrganization Value Fit, and Turnover Intentions. Journal of Public Administration Research and Theory, 18, 205-227. https://doi.org/10.1093/jopart/mum013

Netting, F. E., O’Connor, M. K., \& Yancy, G. (2006). Belief Systems in Faith-Based Human Service Programs. Religion and Spirituality in Social Work: Social Thought, 25, 261-286. https://doi.org/10.1300/J377v25n03_15

Omoto, A. M., \& Snyder, M. (1995). Sustained Helping without Obligation: Motivation, Longevity of Service, and Perceived Attitude Change among AIDS Volunteers. Journal of Personality and Social Psychology, 68, 671-687.

https://doi.org/10.1037/0022-3514.68.4.671

Pargament, K. I. (2013). Spirituality as an Irreducible Human Motivation and Process. International Journal for the Psychology of Religion, 23, 271-281. https://doi.org/10.1080/10508619.2013.795815

Park, S. M., \& Word, J. (2012). Driven to Service: Intrinsic and Extrinsic Motivation for Public and Non-Profit Managers. Public Personnel Management, 41, 705-734.

https://doi.org/10.1177/009102601204100407

Penner, L. A., \& Finkelstein, M. (1998). Dispositional and Structural Determinants of Volunteerism. Journal of Personality and Social Psychology, 74, 525-537. https://doi.org/10.1037/0022-3514.74.2.525

Perry, J. L., \& Wise, L. R. (1990). The Motivational Bases of Public Service. Public Administration Review, 50, 367-373. https://doi.org/10.2307/976618

Perry, J. L., Brudney, J. L., Coursey, D., \& Littlepage, L. (2008). What Drives Morally Committed Citizens? A Study of the Antecedents of Public Service Motivation. Public Administration Review, 68, 445-458. https://doi.org/10.1111/j.1540-6210.2008.00881.x

Reichertz, J. (2007). Abduction: The Logic of Discovery of Grounded Theory. In A. Bryant, \& K. P. Charmaz (Eds.), The Sage Handbook of Grounded Theory (pp. 214-228). Sage. https://doi.org/10.4135/9781848607941.n10

Rey, C., \& Malbasic, I. (2019). Harmonization of Personal and Organizational Purpose. In 
P. Cardona, C. Rey, \& N. Cruz (Eds.), Purpose Driven Organizations: Management Ideas for a Better World (pp. 17-28). Palgrave MacMillan. https://doi.org/10.1007/978-3-030-17674-7_2

Roomkin, M., \& Weisbrod, B. A. (1999). Managerial Compensation and Incentives in For-Profit and Non-Profit Hospitals. Journal of Law, Economics, and Organization, 15, 750-781. https://doi.org/10.1093/jleo/15.3.750

Sheppard, M. (2004). Appraising and Using Social Research in Human Services. Jessica Kingsley.

Star, S., L. (2007). Living Grounded Theory: Cognitive and Emotional Forms of Pragmatism. In A. Bryant, \& K. Charmaz (Eds.), The Sage Handbook of Grounded Theory (pp. 76-93). Sage. https://doi.org/10.4135/9781848607941.n5

Stern, P. N. (2007). On Solid Ground: Essential Properties for Growing Grounded Theory. In A. Bryant, \& K. Charmaz (Eds.), The Sage Handbook of Grounded Theory (pp. 114-126). Sage.

Strauss, A., \& Corbin, J. (1990) Basics of Qualitative Research: Grounded Theory Procedures and Techniques. Sage.

Twiname, L., Samujh, H., \& Van Lamoen, N. (2012). Insights into Turnover among Professional Accountants: Why Are They Leaving? ICSB World Conference Proceedings. Washington, 2, 1-20.

Vallerand, R. J. (2012). From Motivation to Passion: In Search of the Motivational Processes Involved in a Meaningful Life. Canadian Psychology: Ottowa, 53, 42-45.

https://doi.org/10.1037/a0026377

Van Der Westhuizen, D., Pacheco, G., \& Webber, D. J. (2011). Culture, Participative Decision Making and Job Satisfaction. The International Journal of Human Resource Management, 23, 2661-2679. https://doi.org/10.1080/09585192.2011.625967

Wenger, J. L., \& Yarbrough, T. D. (2005). Religious Individuals: Evaluating Their Intrinsic and Extrinsic Motivations at the Implicit Level of Awareness. The Journal of Social Psychology, 145, 5-16. https://doi.org/10.3200/SOCP.145.1.5-16

Wymer, W., Riecken, G., \& Yavas, U. (1996). Determinants of Volunteerism: A Cross-Disciplinary Review and Research Agenda. Journal of Non-Profit and Public Sector Marketing, 4, 3-25. https://doi.org/10.1300/J054v04n04_02 